\title{
Simulation model of a Permanent Magnet Synchronous Generator for grid studies
}

\author{
F. Belloni, R. Chiumeo, C. Gandolfi, A. Villa ${ }^{1}$ \\ ${ }^{1}$ Ricerca sul Sistema Energetico - RSE s.p.a. \\ Via Rubattino 54, 20134, Milano, Italy
}

Phone number:+39 02 39925796, e-mail: belloni@rse-web.it, Riccardo.Chiumeo@rse-web.it,

\section{Chiara.Gandolfi@rse-web.it, Alberto.Villa@rse-web.it}

\begin{abstract}
Permanent Magnet Synchronous Generators are an emerging technology in wind power applications. A simplified Thevenin equivalent simulation model of a wind generator has been developed in the ATPDraw environment and validated by comparing its dynamics with that of a Matlab/Simulink detailed model.

The simplified model includes also power electronic circuits, for interfacing the generator to a MV primary distribution grid, and their controls. A 2,5 MVA wind generator was simulated in ATPDraw in order to assess flicker severity dependence upon different grid and circuit parameters. Simulation results show a strong flicker severity dependence on grid short circuit power and $\mathrm{X} / \mathrm{R}$ line characteristics, in particular when generator supplies reactive power to the grid, as required by some National standards.
\end{abstract}

\section{Key words}

Permanent Magnet Synchronous Generator, simulation models, power electronics, flicker severity assessment.

\section{Introduction}

Onshore and offshore wind power is continuously growing in Europe and worldwide. For instance, wind power's share of total installed power capacity in EU has increased fivefold since 2000; from 2,2\% in 2000 to $11,4 \%$ in 2012 [1]. This trend is confirmed also in the first half of 2013 [2], with a 2020 target of $230 \mathrm{GW}$ of installed wind power in EU [1]. The average power size of new wind turbines is also increasing, reaching the value of 3,8 MW in 2013 [2]. In the recent years, as regards the on-shore plants, which represent the majority of plants currently installed, it is becoming a trend to install average power plants, up to $2 \mathrm{MW}$, based on Permanent Magnets Synchronous Generators (PMSG) instead of doubly-fed induction generators, more diffused in the past. The first, in fact, allows to decouple frequency and voltage level generated by the wind turbine from the network using full power converters. Only in recent years, the power electronics has reached a maturity that allow to make PMSG competitive compared to the traditional solutions, in terms of costs and payback time. In addition, the possibility to easily vary the control strategies of power electronic converters allows to manage the generators in a much more versatile way than the traditional one and, if necessary, to provide auxiliary services to the network [3], [4].

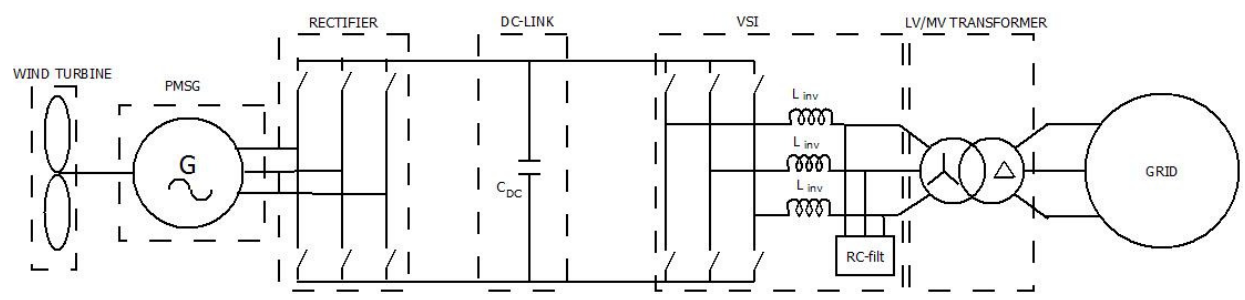

Fig. 1. Block scheme of a Permanent Magnet Synchronous wind Generator and power electronics stages for grid connection.

Grid connected PMSG are interfaced to electric grids through power electronic circuits. A typical scheme of a PMSG based wind system is shown in Fig. 1. The use of two controlled power electronic stages (rectifier and inverter) connected through a DC-link allows:

- a complete decoupling between grid and generator;

- the control of the active power generated by the PMSG, performed through the rectifier;

- the control of active and reactive power supplied to the grid, performed through the inverter.
Sometimes a diode bridge is used as rectifier connected at the output of the PMSG. Even though more expensive, the active rectification is today preferred for larger installation due to the higher efficiency and for the better controllability of the supplied power.

The increasing importance PMSG are gaining pushes for studies devoted to analyses of interactions between the generation system and the grid. Such activities require the development of simulation models of PMSG, power electronic converters and their controls. 
The aim of this work is to describe the implementation, in the ATPDraw environment, of a simplified model of a PMSG interconnected to a distribution grid with power electronic circuits. The validation of the PMSG model is performed comparing its behaviours with a complete model developed in the Matlab/Simulink environment.

The simplified model is then employed to assess the flicker emission of a 2,5 MVA wind generator for different grid conditions. Even though the study cases reported in this work are quite simple, the described modelling approach can be profitably employed for more complex studies [5].

\section{PMSG theoretical model}

Even though the theoretical model of a PMSG wind generator is reported in literature, it's worth recalling here some basic theoretical concepts. As shown in Fig. 1, the system is composed by a wind turbine, a PMSG, a controlled rectifier and a controlled Voltage Source Inverter with an output filter and a MV/LV transformer for grid coupling. It is possible replacing the controlled rectifier with a diode bridge rectifier and a DC/DC converter, but this implementation usually has lower efficiency and less control flexibility.

\section{A. Wind turbine}

The power extracted from the wind by the turbine blades is given by:

$$
P=\frac{1}{2} \rho \pi r^{2} C_{p}(\lambda, \beta) v_{w}^{3}
$$

where $\rho$ is the air density, $r$ is the blade radius, $v_{w}$ is the wind speed and $C_{p}$ is the power coefficients, depending on the tip speed ratio $\lambda$ and on the pitch angle $\beta$ of the blades. $\lambda$ is equal to the ratio of the blades speed and the wind speed. The dependence of $C_{p}$ on $\lambda$ and $\beta$ is shown in Fig. 2 [6].

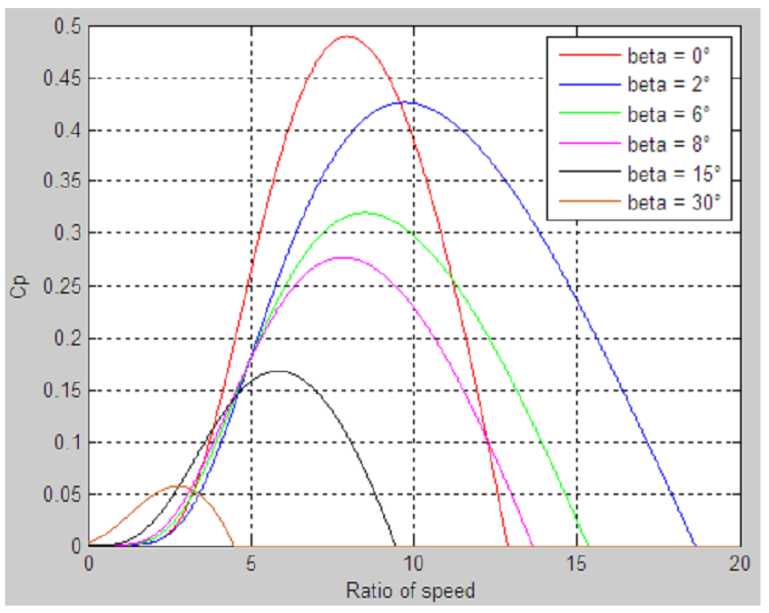

Fig. 2. Power curves dependencies from tip speed ratio at different pitch angles.

\section{B. Permanent Magnet Synchronous Generator}

The dynamic equations governing the operations of a PMSG are:

$$
\begin{aligned}
& \frac{d i_{d}}{d t}=\frac{\omega_{N}}{x_{d}}\left[v_{d}-r_{s} i_{d}+n x_{q} i_{q}\right] \\
& \frac{d i_{q}}{d t}=\frac{\omega_{N}}{x_{q}}\left[v_{q}-r_{s} i_{q}-\left(x_{d} i_{d}+\psi_{M}\right) n\right] \\
& T_{e}=\psi_{M} i_{q}+\left(x_{d}-x_{q}\right) i_{d} i_{q} \\
& \frac{d n}{d t}=\left[T_{e}+T_{m}-B n\right]
\end{aligned}
$$

where:

- $i_{d}, i_{q}$ : generator currents over $\mathrm{d}$ and $\mathrm{q}$ axes;

- $v_{d}, v_{q}$ : generator voltages over $\mathrm{d}$ and $\mathrm{q}$ axes;

- $\omega_{N}$ : electrical angular speed;

- $n$ : turbine rotational speed;

- $x_{d}, x_{q}$ : stator reactances over $\mathrm{d}$ and $\mathrm{q}$ axes;

- $r_{s}$ : stator resistance;

- $\psi_{M}$ : rotor permanent magnet flux;

- $T_{e}, T_{m}$ : electromagentic torque and mechanical torque;

- $B$ : friction coefficient.

All quantities of $(2) \div(5)$ are expressed in a d-q rotating frame synchronous to the PMSG rotor flux. In a round rotor machine $\left(\mathrm{x}_{\mathrm{d}}=\mathrm{x}_{\mathrm{q}}\right)$, from (4) it emerges that the generator active power is proportional to the quadratureaxis current $\mathrm{i}_{\mathrm{q}}$ which is the main electrical control parameter.

\section{Controlled rectifier}

The controlled rectifier circuit allows the generation of three voltages at the outputs of the PMSG with wanted amplitudes and angles by acting on the open/close status of the six controlled switches. The currents supplied by the PMSG depends on these voltages and on the leakage inductances of the generator. Starting from $(2) \div(5)$, it is convenient to express voltages over $d-q$ axes, so that the circuit can control the direct and quadrature current supplied by the generator. Even though different control schemes are applicable, here the so called field oriented control is used [3]. Control block scheme is represented in Fig. 3. In the adopted control scheme, the rotating speed of the PMSG rotor is compared to a reference value, calculated by a Maximum Power Point Tracking (MPPT) loop, and the speed error is processed by a Proportional-Integral-Derivative (PID) regulator, in the form:

$$
H_{P I D}(s)=k_{p}+\frac{k_{i}}{s}+k_{d} s
$$

where $\mathrm{k}_{\mathrm{p}}$ is the proportional gain, $\mathrm{k}_{\mathrm{i}}$ the integral gain and $\mathrm{k}_{\mathrm{d}}$ the differential gain. The rotating speed reference is chosen by a MPPT in order to maximize (1).

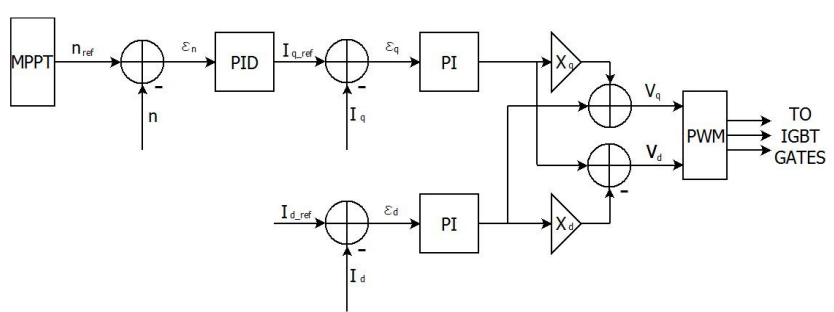

Fig. 3. Rectifier control block scheme. 
The output of the PID regulator represents the q-axis current reference for the rectifier, while the $d$-axis reference is kept to zero in order to minimize losses. Both current references are compared with the relevant current values and errors are processed by two ProportionalIntegral (PI) regulators, in the form:

$$
H_{P I}(s)=k_{p}+\frac{k_{i}}{s}
$$

where again $\mathrm{k}_{\mathrm{p}}$ represents the proportional gain and $\mathrm{k}_{\mathrm{i}}$ the integral gain. Outputs of the regulators are further processed for obtaining three modulating signals which are sent to a Pulse Width Modulation (PWM) stage for the generation of 6 command signals for the controlled switches of the rectifier.

\section{Voltage Source Inverter}

The Voltage Source Inverter (VSI) topology employed in this work is a three-legs bridge, with IGBT switches. The control scheme for the VSI is represented in Fig. 4.

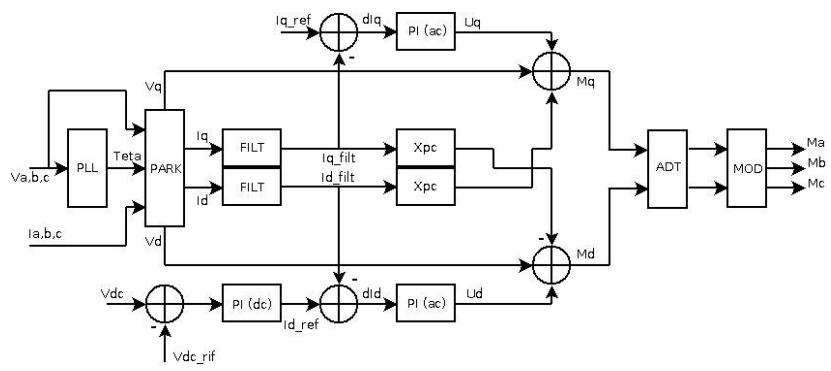

Fig. 4. Voltage source inverter control.

Again, the control aims at the regulation of the inverter currents represented on the rotating $d-q$ axes. In this case, rotating frame is synchronous to the grid voltages.
Adopting such a reference frame allows controlling separately the inverter active power, proportional to the $i_{d}$ current, and the inverter reactive power, proportional to the $i_{q}$ current. The $i_{d}$ reference value is calculated by an outer voltage loop by processing through a PI regulator the difference between the DC-link voltage and a reference value. In this way, the DC-link voltage is maintained constant and all the active power coming from the rectifier is supplied to the grid. In fact:

$$
\begin{aligned}
& \frac{d V_{D C}}{d t}=0 \Rightarrow i_{C}=0 \Rightarrow i_{\text {rect }, D C}=i_{i n v, D C} \Rightarrow \\
& \Rightarrow P_{\text {rect }}=P_{i n v}
\end{aligned}
$$

where $V_{D C}$ is the DC-link voltage, $i_{C}$ is the DC-link capacitor current, $i_{\text {rect,DC }}$ is the DC current of the rectifier, $\mathrm{i}_{\text {inv, } D C}$ is the DC current of the inverter, $P_{\text {rect }}$ is the active power of the rectifier and $\mathrm{P}_{\text {inv }}$ the active power of the inverter.

The q-axis current reference is usually set to zero in order to minimize conduction losses, but different values can be possible in some cases, according to different National standards. For instance the Italian standard [7] requires that the inverter should exchange reactive power in case of grid under-voltage or over-voltage. For this reason, a suitable outer loop for the calculation of the $i_{q}$ reference is added to the control. The coupling of the inverter to the MV distribution grid is made with a LV/MV transformer which windings ratio and their relative phase displacement must be taken into account within the control of the inverter.

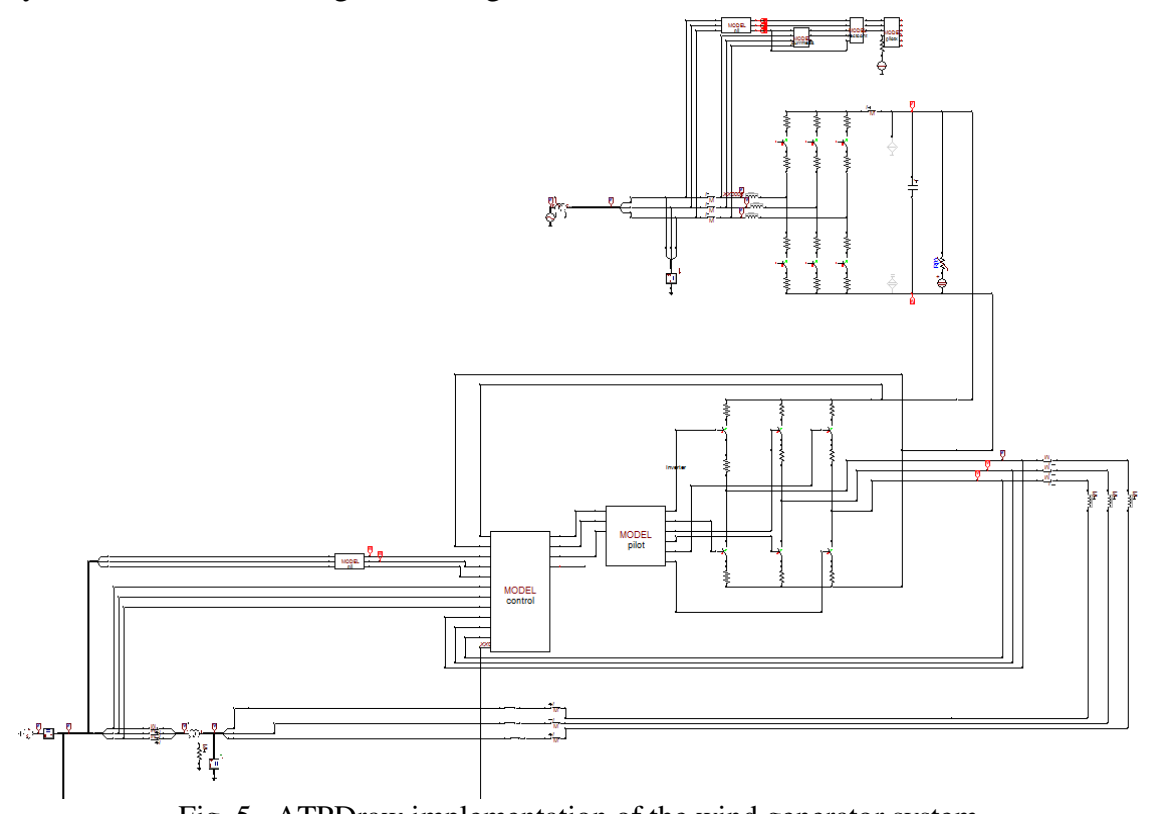

Fig. 5. ATPDraw implementation of the wind generator system.

\section{Wind generator simplified model in ATPDraw}

A simplified model of a wind PMSG system has been developed into the Alternative Transient Program Draw
(ATPDraw) environment ${ }^{1}$. The ATPDraw implementation of the generator system is represented in Fig. 5, where main parts are put into evidence.

\footnotetext{
${ }^{1}$ ATPDraw, version 5.7p6.
} 


\section{A. Permanent Magnet Synchronous Generator model}

The PMSG is here represented through an ideal voltage three phase generator with leakage inductances and resistances connected in series to the outputs (Thevenin equivalent) [8]. Such a simplification in the generator representation, that should be validated, allows reducing the computational complexity of evaluating the solution of the equations $(2) \div(5)$. In this way, it is possible to insert the simplified PMSG model within larger system in order to perform study of Distributed Generators (DG) integration within complex distribution grids [5]. The model validation is discussed in the next section.

\section{B. Power electronic circuits models}

Both controlled rectifier and VSI are represented with their switching behaviours. For simplicity, switches are represented only with their conduction status, being $\mathrm{ON}$ or OFF, dependent on a logical gate signal. At the ACoutputs of the inverter three inductors are connected and a shunt filter is added for high frequency harmonics attenuation. Detailed controls of both the circuits, according to the schemes of Fig. 3 and Fig. 4, have been implemented using ATPDraw models. Since a Thevenin equivalent is used as PMSG model, no rotating speed regulation is needed. For this reason, the rotating speed control loop of Fig. 3 is not implemented in the simplified model. LV/MV transformer with nonlinear magnetizing curve is employed for grid coupling.

A 2,5 MVA wind generator was used in this work. Main design parameters of the machine are given in TABLE I.

TABLE I. 2,5 MVA wind generator main design parameters.

\begin{tabular}{|c|c|c|}
\hline \multicolumn{3}{|c|}{ Rectifier } \\
\hline Nominal power & $\mathrm{A}_{\mathrm{Nr}}$ & $2,5 \mathrm{MVA}$ \\
\hline Nominal AC voltage & $\mathrm{V}_{\mathrm{CA}, \mathrm{N}}$ & $400 \mathrm{~V}$ \\
\hline Switching frequency & $f_{\mathrm{SW}}$ & $1950 \mathrm{~Hz}$ \\
\hline \multicolumn{3}{|c|}{ DC-Link } \\
\hline Nominal voltage & $\mathrm{V}_{\mathrm{DCN}}$ & $1100 \mathrm{~V}$ \\
\hline Maximal voltage & $\mathrm{V}_{\mathrm{DCmax}}$ & $1400 \mathrm{~V}$ \\
\hline Capacitance & $\mathrm{C}_{\mathrm{DC}}$ & $100 \mathrm{mF}$ \\
\hline \multicolumn{3}{|c|}{ Inverter } \\
\hline Nominal power & $\mathrm{A}_{\mathrm{Ninv}}$ & 2,5 MVA \\
\hline Inductance & $\mathrm{L}_{\text {inv }}$ & $7,64 \mu \mathrm{H}(4 \%)$ \\
\hline Filter resistance & $\mathrm{R}_{\text {filt,inv }}$ & $10 \mathrm{~m} \Omega$ \\
\hline Filter capacitance & $\mathrm{C}_{\text {filt,inv }}$ & $5 \mathrm{mF}(\mathrm{fr}=814 \mathrm{~Hz})$ \\
\hline Switching frequency & $f_{\text {sw }}$ & $1950 \mathrm{~Hz}$ \\
\hline \multicolumn{3}{|c|}{ LV/MV Transformer } \\
\hline Nominal power & $\mathrm{A}_{\mathrm{Ntr}}$ & $3 \mathrm{MVA}$ \\
\hline Leakage inductance & $\mathrm{L}_{\mathrm{k}}$ & $3,5 \mu \mathrm{H}(7 \%)$ \\
\hline Winding ratio & $\mathrm{n}$ & $20000 / 220$ \\
\hline Winding coupling & & Dy11n \\
\hline \multicolumn{3}{|c|}{ Rectifier control } \\
\hline \multirow{2}{*}{ PI regulators } & \multirow{2}{*}{$\mathrm{H}_{\mathrm{PI}, \mathrm{r}}(\mathrm{s})$} & $0,1 s+2$ \\
\hline & & $s$ \\
\hline \multicolumn{3}{|c|}{ Inverter control } \\
\hline \multirow{2}{*}{ DC voltage PI regulator } & \multirow{2}{*}{$\mathrm{H}_{\mathrm{PI}, \text { vinv }}(\mathrm{s})$} & $0,0289 s+1$ \\
\hline & & $0,009 s$ \\
\hline \multirow{2}{*}{ Current loop regulators } & \multirow{2}{*}{$\mathrm{H}_{\mathrm{PI}, \mathrm{iinv}}(\mathrm{s})$} & $0,2769 s+1$ \\
\hline & & $0,0028 s$ \\
\hline
\end{tabular}

\section{MV distribution grid model}

For this work, a simplified Thevenin equivalent model of a MV distribution grid is employed. The short circuit power and the $\mathrm{X} / \mathrm{R}$ characteristic of the grid at the point of connection of the wind generator can be varied by changing the equivalent line impedance.

\section{Wind generator detailed model in Matlab/Simulink}

A detailed model of a Permanent Magnet Synchronous Generator was developed in the Matlab/Simulink environment by implementing $(2) \div(5)$ through Simulink blocks, as represented in Fig. 6.

The inputs of the system are the voltages generated by the controlled rectifier, which was also represented in Simulink as an averaged model [9]. The inputs of the PMSG are the voltages generated by the rectifier, expressed in the rotating d-q frame, and its outputs are the d-axis current, the q-axis currents and the angular speed of the generator, which are used as inputs for the rectifier control. The inverter is not represented here, but a resistor is connected in parallel to the DC-link capacitor in order to drain the exact power produced by the PMSG.

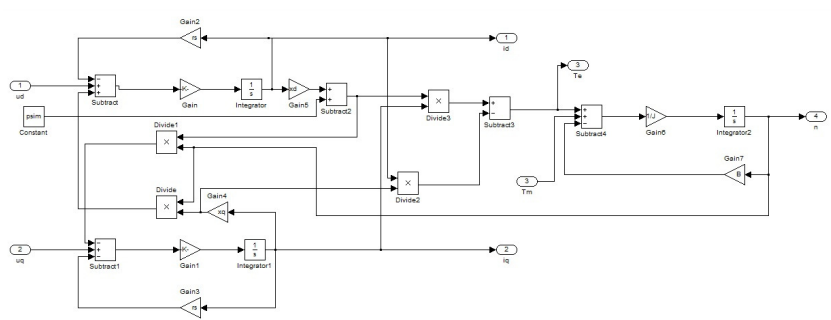

Fig. 6. Simulink detailed implementation of a PMSG.

\section{PMSG simplified model validation}

The validation of the simplified model is made by comparing its dynamic behaviour with that of the Matlab detailed model. Some difference should be considered though:

- in the Thevenin equivalent active power is proportional to the d-axis current, while in the detailed model it is proportional to the q-axis current;

- similarly, the reactive power is proportional to the qaxis current for the simplified and to the d-axis current for the detailed model;

- the simplified model rotational speed is fixed, while in the detailed model it can vary around the reference value during transients;

- the voltage output of the detailed model can vary, while for the Thevenin equivalent it is fixed at its nominal value.

Dynamic comparisons have been made for the 2,5 MVA PMSG. Simulation results for both models are reported in Fig. 7, where the behaviour of $i_{d}$ and $i_{q}$ for both model are represented in case of a step change of generated active power.

As it can be seen, the dynamics of the simplified model is very close to that of the detailed model, a part from the unavoidable differences already pointed out. The detailed model seems to shows less dumped dynamics, probably due to the absence of parasitics in the model of the rectifier and to the missing interactions with the inverter 
dynamics. For the purposes of this paper the two models are equivalent, also considering that both the DC-link capacitor and the inverter decouples the PMSG from the distribution grid. For this reason, the flicker assessments

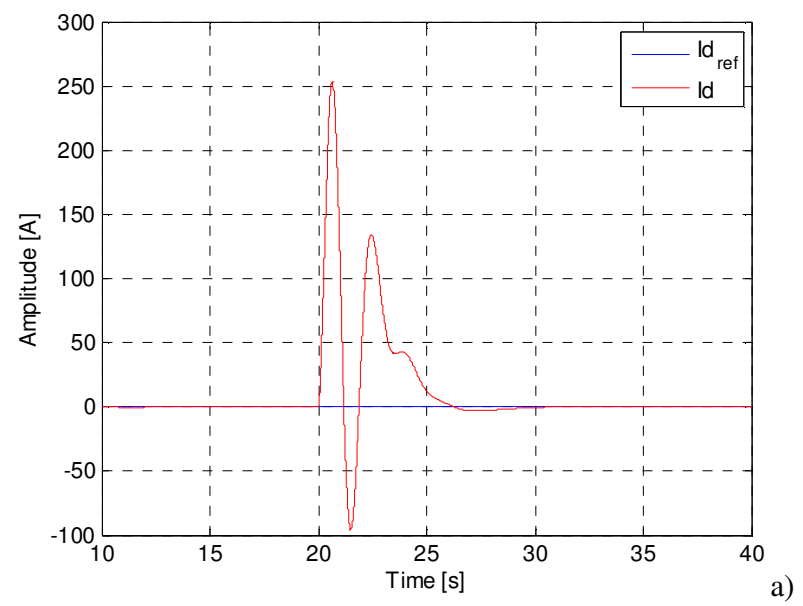

a)

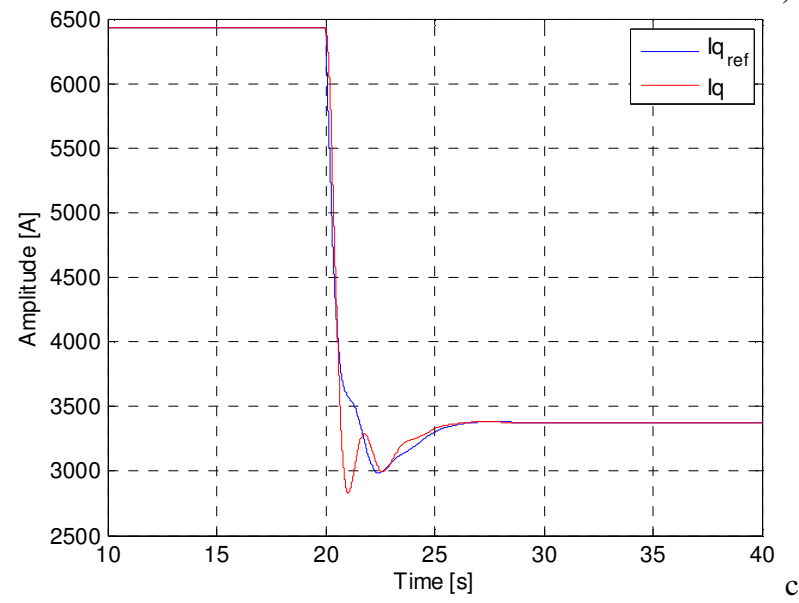

c) reported hereafter were performed with the ATPDraw simplified model only.
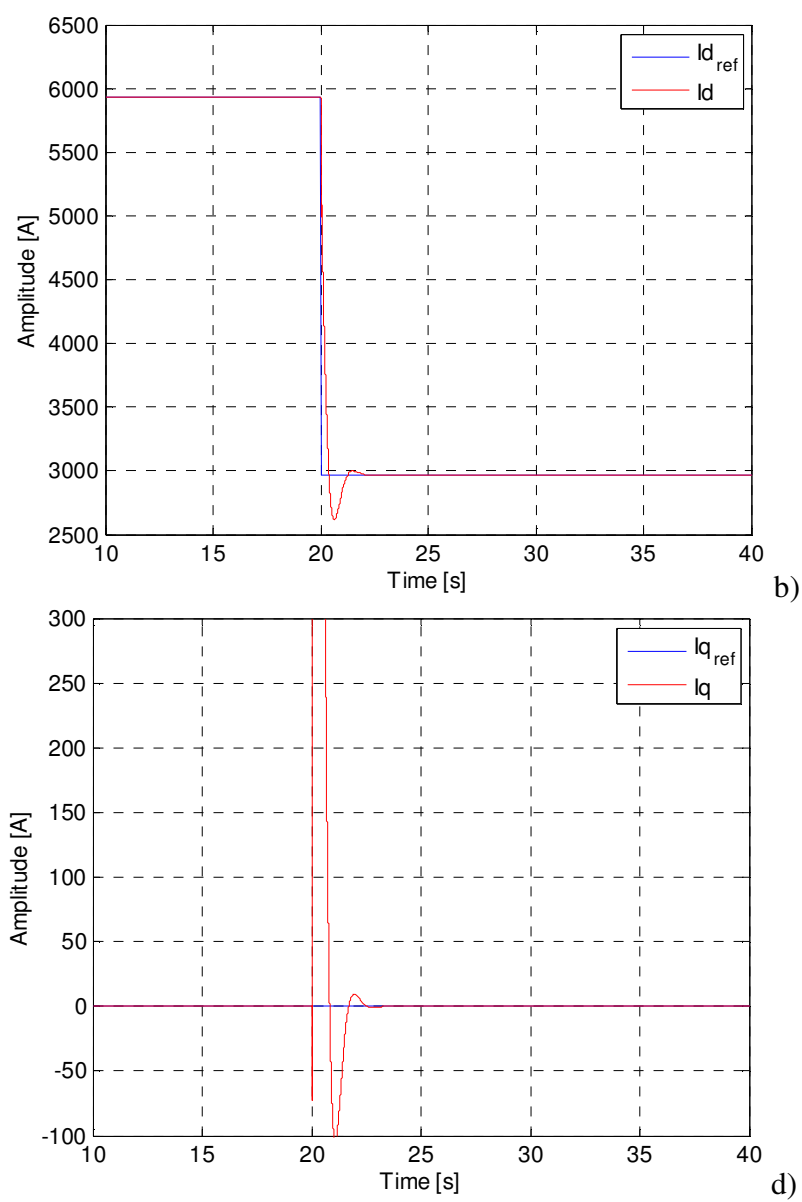

d)

Fig 7. Dynamic behaviour of generator currents calculated from the detailed model of a PMSG $(\mathrm{a}$ and $\mathrm{b})$ and from the simplified model (c and d) in case of a step change of the active power. It should be noted that $i_{d}$ and $i_{q}$ exchange their role in the two models.

\section{PMSG flicker assessment}

For the calculation of the flicker emission of the PSMG, a flickermeter digital model was implemented into Matlab according to [10]. The flickermeter model was fed by grid voltages calculated through the ATP simplified model.

Due to simulation time constrains, only the short term flicker coefficient $\mathrm{P}_{\mathrm{st}}$ was evaluated and it was calculated for $1 \mathrm{~s}$ ([10] requires a calculation of $\mathrm{P}_{\mathrm{st}}$ over 10 minutes). Even though the short term flicker coefficient here calculated is not in accordance to the standard [10], it is useful to assess the influence of some grid and generator parameters on flicker severity.

In order to produce flicker in the grid, active power variations of the primary source were simulated, as in case of wind gusts. In the simplified model power variations were implemented by superimposing a sawtooth waveform with a given frequency to the d-axis current reference in the control loop of the rectifier. Variations of $\pm 0,08 \mathrm{pu}( \pm 200 \mathrm{~kW})$ of active power were considered, correspondent to variations of $\pm 0,08$ pu of the current reference. Three type of parameter variations were considered [11]:

- grid short circuit power at the point of connection of the inverter;
- line X/R characteristic;

- capacitance of the DC-link.

$\mathrm{P}_{\text {st }}$ values are repeatedly calculated varying each considered parameter over a given range. Simulations are performed with generator supplying power at different power factors. The main results are reported in the next figures. In particular it's possible to say that:

- during generation/consumption of reactive power the $\mathrm{P}_{\mathrm{st}}$ increase and this index presents reverse dependency from the grid Short Circuit (Fig. 8);

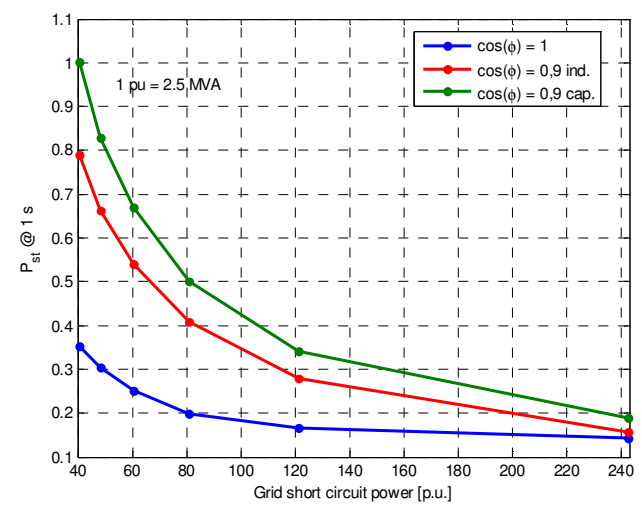

Fig. 8. Flicker severity dependence on short circuit power of the MV grid at the point of connection of the generator. 
- the $\mathrm{P}_{\mathrm{st}}$ index is more influenced by the resistive part of the line impedance independently from grid short circuit power (Fig. 9);

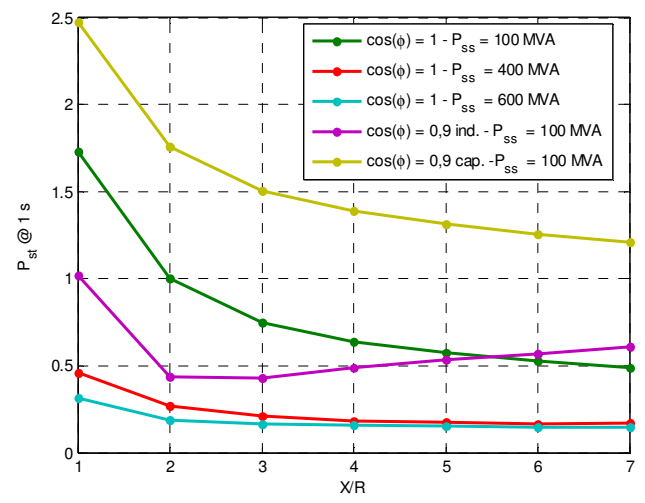

Fig. 9. Flicker short term index dependence on $\mathrm{X} / \mathrm{R}$ line characteristics.

- the $\mathrm{P}_{\mathrm{st}}$ index is less influenced by the DC-link capacitor, in Fig. 10 a $40 \%$ variation of the nominal value of the DC capacitor has been considered.

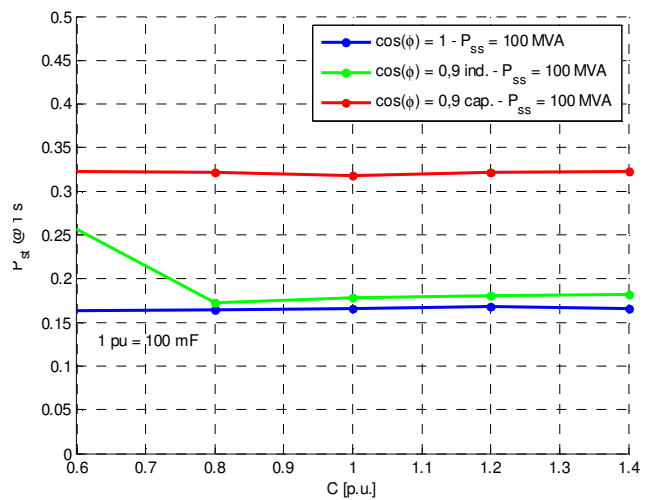

Fig. 10. Flicker severity dependence on DC-link capacitance.

\section{Conclusions}

The paper presents the implementation of a simplified Thevenin equivalent model of a Permanent Magnet Synchronous Generator (PMSG) for wind power applications. Such a simplification in the generator representation allows reducing the computational complexity of evaluating the solution of the dynamic equations. In this way, it is possible to insert the simplified PMSG model within larger system in order to perform study of Distributed Generators integration within complex distribution grids.

The simplified model of the PMSG is developed in the ATPDraw environment, together with models of power electronic circuits and their controls. The dynamic behaviours of the simplified model are compared with those of a detailed PMSG model developed in Matlab/Simulink and a good compliance is found. The simplified model is employed for the assessment of flicker severity from a 2,5 MVA wind power system connected to a MV distribution grid for different grid and generator parameters values. Simulation results show a strong dependence of the flicker severity on the short circuit power of the grid and on the $\mathrm{X} / \mathrm{R}$ line characteristic, in particular when the generator supplies reactive power to the grid. Simulations also show a weak dependence of the flicker severity from the DC-link capacitance.

Even though the reported case studies are quite simple, such a simplified modelling approach is suited to be employed in complex grid studies, where a number of generators are connected simultaneously at a complex grid.

\section{Acknowledgement}

This work has been financed by the Research Fund for the Italian Electrical System under the Contract Agreement between RSE S.p.A. and the Ministry of Economic Development - General Directorate for Nuclear Energy, Renewable Energy and Energy Efficiency in compliance with the Decree of March 8, 2006.

\section{References}

[1] European Wind Energy Association, "Wind in power - 2012 European statistics", web site: http://www.ewea.org/fileadmin/files/library/publications/statistic s/Wind_in_power_annual_statistics_2012.pdf.

[2] European Wind Energy Association, "The European offshore wind industry - key trends and statistics 1st half 2013": http://www.ewea.org/fileadmin/files/library/publications/statistic s/EWEA_OffshoreStats_July2013.pdf.

[3] O.B.K. Hasnaoui, J. Belhadj, M. Elleuch, "Direct drive permanent magnet synchronous generator wind turbine investigation", in Journal of electrical systems, Vol. 4, Issue 3, September 2008, pp. 1-13.

[4] E. Mahersi, A. Khedher, M. Faouzi Mimouni, "The wind energy conversion system using PMSG controlled by vector control and SMC strategies", International Journal of Renewable Energy Research, Vol. 3, N.1, 2013.

[5] F. Belloni, R. Chiumeo, C. Gandolfi, , "Permanent magnet wind generators: control strategies to manage voltage unbalances", International Conference on Renewable Energies and Power Quality, ICREPQ2012, Santiago de Compostela, Spain, 28-30 March 2012.

[6] K. Belmokhtar, M. Lamine Doumbia, K. Agbossou, "Modelling and Power Control of Wind Turbine Driving DFIG connected to the Utility Grid", in Proc. of the International Conference on Renewable energies and Power Quality, ICREPQ 2011, Las Palmas de Gran Canaria (Spain), 13th to 15th April, 2011, pp. 1-6.

[7] CEI 0-16, "Regola tecnica di riferimento per la connessione di Utenti attivi e passivi alle reti AT ed MT delle imprese distributrici di energia elettrica", Italian standard.

[8] J. Mur-Amada, A. A. Bayod-Rujula, "Flicker emission of wind farm during continuous operation", IEEE Transaction on Energy conversion, vol. 17, Issue 1, March 2012, pp. 114-118.

[9] N. Mohan, T.M. Undeland, W.P. Robbins, "Power Electronics: Converters, Applications, and Design”, John Wiley and Sons inc., Third edition.

[10] IEC 61000-4-15, "Electromagnetic compatibility (EMC) part 4: testing and measurement techniques - section 15: flickermeter functional and design specification”, Ed. 2.0, 2010.

[11] L. Meegahapola, A. Perera, "Impact of wind generator control strategies on flicker emission in distributed networks", 15th IEEE International Conference on Harmonics and Quality of Power, ICHQP2012, Hong Kong, 17-20 June 2012, pp. 1-6. 